Etnográfica

Revista do Centro em Rede de Investigação em

Antropologia

vol. $19(2) \mid 2015$

Vol. $19(2)$

\title{
Das nomeações às representações: os palavrões numa interpretação inspirada por H. Lefebvre
}

From namings to representations: swear words in an interpretation inspired by H. Lefebvre

José Machado Pais

\section{(2) OpenEdition}

Journals

Edição electrónica

URL: https://journals.openedition.org/etnografica/4000

DOI: $10.4000 /$ etnografica. 4000

ISSN: 2182-2891

\section{Editora}

Centro em Rede de Investigação em Antropologia

Edição impressa

Data de publição: 1 junho 2015

Paginação: 267-289

ISSN: 0873-6561

\section{Refêrencia eletrónica}

José Machado Pais, «Das nomeações às representações: os palavrões numa interpretação inspirada por H. Lefebvre», Etnográfica [Online], vol. 19 (2) | 2015, posto online no dia 22 junho 2015, consultado o 09 fevereiro 2022. URL: http://journals.openedition.org/etnografica/4000 ; DOI: https://doi.org/ 10.4000/etnografica. 4000

\section{(c) (i) (8)}

Etnográfica is licensed under a Creative Commons Attribution-NonCommercial 4.0 International License. 


\section{Das nomeações às representações: os palavrões numa interpretação inspirada por $\mathrm{H}$. Lefebvre}

\section{José Machado Pais}

Ao ganharem o estatuto de palavrões, por que razão algumas palavras se tornam interditas ou apenas evocadas através da mediação de alegorias e metáforas sugeridas por outras palavras? Para responder a este enigma, convocam-se as teorias da presença-ausência, propostas por Lefebvre, abordando-se dimensões de análise - o inconsciente, o imaginário, a cultura - frequentemente desconsideradas quando oscilamos entre o representante e o representado, desprezando a representação. $\mathrm{Na}$ esteira do método regressivo-progressivo, a análise dos palavrões evidencia a ordem caótica de significações que faz sobreviver o enigma da representação. As mediações entre o vivido, o percebido e o concebido mostram-nos que, por detrás do limbo das palavras e dos palavrões, encontramos um amplo campo de análise social.

PALAVRAS-CHAVE: imaginários, Lefebvre, linguagem, palavrões, representações, sexualidade.

From namings to representations: swear words in an interpretation inspired by $\mathrm{H}$. Lefebvre - In acquiring the status of swear words, why do some words become prohibited or are only evoked through the mediation of allegories and metaphors suggested by other words? In order to answer this riddle, Lefebvre's theories of presence-absence are called on, addressing dimensions of analysis - the unconscious, imagination, culture - often disregarded when we swing between the representative and the represented, ignoring representation. In line with the regressive-progressive method, the analysis of swear words highlights the chaotic order of meanings which causes the riddle of representation to survive. Mediations between what is lived, perceived and conceived show us that behind the literal meaning of words and swear words we may find ample scope for social analysis.

KEYWORDS: imagination, Lefebvre, language, swear words, representations, sexuality.

PAIS, José Machado (machado.pais@ics.ulisboa.pt) - Instituto de Ciências Sociais, Universidade de Lisboa (ULisboa), Portugal. 
QUANDO, EM SUA CONHECIDA OBRA LA PRÉSENCE ET L'ABSENCE, Henri Lefebvre (1983 [1980]) se propôs abordar as representações, matutou consigo mesmo: que diriam as pessoas se lhes perguntássemos como representariam a sexualidade ou o sexo? Uma boa parte dos interrogados, suspeitou Lefebvre, responderia com gracejos, ironias ou subterfúgios - o que não deixaria de ser significativo, pois os sentidos da linguagem também se revelam através de subentendidos ou conteúdos obscuros. Contudo, para Lefebvre, uma tal abordagem, com perguntas e respostas, correria o risco de um duplo desconhecimento. Por um lado, o das representações ocultas, não diretamente questionadas. Por exemplo, haverá diferenças de género nas representações do sexo feminino? Por outro lado, correríamos o risco de negligenciar as situações concretas (o vivido) em que se produzem ou circulam as representações (Robinson 2003). É aqui que Lefebvre levanta uma hipótese teórica e estratégica: o mesmo não pode representar-se a si mesmo, já que a identidade só se realiza através da diferença. Vejamos, no exemplo sugerido, onde nos levaria essa mesma hipótese. Desde logo, ao reconhecimento de que "o masculino tende a representar-se no, por e através do feminino" (Lefebvre 1983 [1980]: 168), ainda que o feminino apareça representado por uma ausência. Como chegamos a perceber o sistema de relações entre estes trâmites? Lefebvre aponta-nos um caminho, o das mediações, alertando-nos, contudo, para o facto de a representação não se poder reduzir a uma imagem espelhada, a um simples reflexo, muito pelo contrário. Eis aqui um vasto campo muito pouco explorado no domínio das ciências sociais: o das mediações na análise das representações. Uma investida por estes domínios de pesquisa requer uma metodologia orientada pela busca oblíqua de presenças na ausência. Essa metodologia, pioneiramente desenvolvida por Henri Lefebvre, ${ }^{1}$ é retomada e discutida no presente artigo, em diálogo com outros contributos teóricos vindos sobretudo da antropologia, da sociologia e da sociolinguística. ${ }^{2}$ Para o efeito toma-se por objeto de estudo o enigma dos palavrões. Como interpretar o pudor social no

I Com uma vastíssima obra que reúne mais de meia centena de livros, e apesar ou justamente por causa de sua formação filosófica, Henri Lefebvre (1901-1991) não deixou de se afirmar em domínios como os da sociolinguística, da história ou da sociologia. A sua sensibilidade antropológica em muito se deve à sua experiência de vida quando, depois de ter cumprido o serviço militar no Norte de África, regressa a Paris para trabalhar como operário na Citroën e, posteriormente, como taxista. Com efeito, uma boa parte da sua produção teórica centra-se na crítica da vida quotidiana, na produção do espaço e na alienação social. Em 1970, Henri Lefebvre fundou com Anatole Hopp a revista Espace et Société que, após a sua morte, lhe consagrou um número de homenagem (n. $\left.{ }^{\circ} 76,1994\right)$. A obra de Henri Lefebvre tem sido recentemente alvo de um recrudescido interesse (Shields 1999; Elden 2004; Stanek 2011; Butler 2012).

2 Num esforço que procura confluências disciplinares, como também se verifica no clássico estudo de Paul Rabinow (1986) sobre representações sociais. 
uso dos palavrões? Por que se calam tais palavras quando saem do mundo do calão? Que sentidos estranhos as transformam em palavras obscenas?

Não de todo apartados do universo da gíria e do calão, os estudos sobre os palavrões têm explorado inevitáveis interconexões entre linguagem, sexualidade e sociedade (Mattiello 2008; Cameron e Kulick 2003). Aspetos relacionados com ofensas verbais e códigos de honra no uso dos palavrões têm também merecido a atenção da antropologia (Blok 1981) e da sociolinguística (Sandmann 1993). Os interditos à circulação dos palavrões, frequentemente associados aos tabus sexuais, também têm atraído um crescente interesse de cientistas sociais de diferentes quadrantes disciplinares - não apenas da antropologia, com pioneiros contributos neste campo de análise (Leach 1973 [1964]), mas também da psicologia (Jay 2009), da psicanálise (Arango 1996) ou da sociolinguística (Anderson e Trudgill 1990). No entanto, falta aprofundar o diálogo entre estes diferentes contributos disciplinares. Este repto é tido em conta na proposta de análise sobre os palavrões que adiante se ensaia, ainda que o método regressivo-progressivo de Lefebvre adquira uma relativa centralidade teórica.

Embora nunca o tenha sistematizado, o método regressivo-progressivo está implicitamente presente em grande parte da obra de Lefebvre. O descritivo, o histórico-genético e o analítico regressivo (Lefebvre 1953, 1989 [1959]) constituem os componentes essenciais do método que logo mereceu uma calorosa recetividade por parte de Sartre (2002 [1960]). As teorias da presença-ausência (Lefebvre 1983 [1980]) - levando em linha de conta o descritivo (no caso em estudo: os palavrões explícitos ou que implicitamente se afirmam em sua ausência quando invocados por outras palavras ou expressões) e o histórico genético (a descoberta dos meandros históricos e sociais na génese dos palavrões) - permitem-nos dar conta de um importante achado, num registo analítico-regressivo: as significações que saltam à vista encobrem outros sentidos, não apenas em profundidade, mas frequentemente em extensão, isto é, quer na historicidade do que se passa à superfície da vida quotidiana, quer na mutabilidade do vivido. As mediações propostas entre o vivido, o percebido e o concebido mostram-nos que, por detrás do limbo das palavras e dos palavrões, encontramos um amplo campo de análise social. Por isso mesmo, os achados da linguística não passaram despercebidos à antropologia desde a pioneira obra de Marcel Mauss (Karsenti 1997).

\section{O MÉTODO REGRESSIVO-PROGRESSIVO APLICADO À LINGUAGEM}

Aplicado aos fenómenos da linguagem, o método regressivo-progressivo, ancorando as falas do presente aos enlaces sociais da historicidade e mutabilidade do vivido, aparece como uma estratégia orientada para a busca de sentido. Mas não onde supostamente esse sentido poderia parecer mais evidente, na 
significação: "A significação é literal. O sentido remete-se de todos os lados para outra coisa: para o passado, para o adquirido, para a atualidade, para a memória, por um lado - e, por outro lado, para o virtual, para os possíveis, para a diversidade dos campos percetíveis carregados de sentido" (Lefebvre 1968 [1966]: 215). Ao mesmo tempo cintilante e fugidio, o sentido acabaria por surgir de uma espécie de opacidade. Estamos num campo de debate semiológico que - como viria a ser reconhecido por Melandri (1968) - abre portas a uma hermenêutica tensional entre a sintomatologia (onde o signo aparece numa relação de causalidade com o designado) e a simbologia (onde essa relação de causalidade não faz sentido). Melandri (1968) sugere, aliás, uma isomorfia entre a distinção freudiana que coloca o consciente ante o inconsciente e a distinção semiológica que coloca frente a frente a historiografia e a história real (a que tem de ser resgatada). Então, a história crítica, a que promove o resgate, assemelhar-se-ia a uma espécie de terapia cujo objetivo seria o de recuperar o inconsciente, entendido como o histórico removido. No campo aberto por esta rutura epistemológica podemos situar o método regressivo-progressivo de Lefebvre, a arqueologia do saber de Foucault (1966, 1969, 1971) e o método regressivo-arqueológico de Melandri (1968). Em qualquer dos casos há um rastreio da genealogia real dos acontecimentos até se chegar a uma bifurcação de registos do fenómeno indagado - como a que opõe, no caso da psicanálise, o consciente ao inconsciente. Segundo Melandri, não se trata de chegar ao inconsciente enquanto tal, mas de desvendar os fatores, circunstâncias ou processos que fizeram do inconsciente o que ele é, no sentido dialético de removido. O procedimento regressivo tem esse objetivo: o de lidar com o removido. A história crítica é aquela que é capaz de recuperar o alienado, o excluído, o removido, através da contraposição dialética entre racionalização e sublimação.

Essa preocupação em fazer pulsar o removido encontra-se bem presente no método regressivo-progressivo de Lefebvre, dada a sua valorização das temporalidades da história (Martins 2003). Nos seus estudos sobre linguagem e sociedade, o que Lefebvre (1968 [1966]) nos mostra é que a palavra tem uma inscrição temporal que lhe dá um valor mutável. Essa variabilidade decorre da mobilidade dos significados das palavras, pois elas são andantes (Galeano 2004), aladas (do latim alatus: "que tem asas"). Mas essa capacidade de voo pressupõe um espaço de aterragem, um lugar de circulação ou de pouso (Nichols 1992) - seja ele um espaço de escrita (uma folha de papel, uma lousa, um ecrã de computador) ou de interação, onde a palavra possibilita a comunicação. É precisamente esta relação entre tempo e espaço que o método regressivo-progressivo explora, permitindo que a linguagem deixe de ser considerada um saco de palavras, isto é, uma língua-nomenclatura, com significação e sentidos precisos, inquestionáveis. No saco de palavras, cada palavra designa uma coisa, um objeto, um ser. Com Lefebvre, à boleia de Saussure (1997 [1916]), abalou-se 
esta estabilidade. Porém, Lefebvre esquiva-se à tendência saussuriana de fetichização da linguagem (Arrivé 2007), posicionamento que deixaria escapar o sentido mais profundo do que se nomeia: "A representação dissolve-se no signo, unidade de dois termos e duas caras, o significante e o significado, o representante e o representado. Mas que sucede com o sentido?" (Lefebvre 1983 [1980]: 23). É essa busca de sentido que mobiliza Lefebvre para o estudo da linguagem, ao considerá-la um "tesouro do conhecimento".

Para chegar a esse tesouro há que explorar e deslindar o vínculo entre linguagem e sociedade. Manifestando-se crítico em relação aos que defendem que a significação se define pela denotação (o conteúdo, o significado), Lefebvre sugere que, pelo contrário, o que se consegue exprimir empobrece frequentemente o sentido. O que se exprime é apenas vibração do sentido. Daí o desafio de passar do expressivo (descrição) para o significativo (interpretação), tendo em vista o tesouro da linguagem. Tesouro porquê? Porque a linguagem é um núcleo central de descobertas, uma "metáfora cheia de promessas" (Lefebvre 1968 [1966]: 15). É aqui que o procedimento regressivo, tão caro à psicanálise, representa para Lefebvre um verdadeiro desafio metodológico. Aliás, o próprio acaba por reconhecer que a psicanálise abriu caminho para a descoberta desse tesouro ao promover o questionamento da linguagem e ao incitar a descoberta de tensões, simultaneamente reveladas e dissimuladas, de necessidades e desejos, "normalidades" e "desvios" (Lefebvre 1968 [1966]: 15). O método analítico-regressivo de Lefebvre projeta-se nesse campo de tensões que se cruzam entre a superfície do observável e a sua subterraneidade, entre o que se dissimula e o que se descobre que é, no fundo, o social.

Esta aposta nas estruturas da ausência é uma estratégia de busca de sentido na obscuridade das conotações. Elas arrastam as denotações para um mundo de outras significações: "o número treze tem uma denotação clara (treze convidados, treze ovos) e uma conotação obscura para as pessoas supersticiosas" (Lefebvre 1968 [1966]: 107). Ou seja, surgem frequentes desdobramentos da conotação, através das aberturas que se produzem entre significante e significado. O desafio não é propriamente o de privilegiar o oculto sob o aparente - o que se dissimula ou oculta - em detrimento do evidente. É a relação entre o evidente e o oculto (Pais 2002: 65-68) que interessa ter em mira para rasgar os véus que as representações tecem à sua volta, obnubilando o sentido emaranhado numa outra relação: a que se estabelece entre representado, representante e representação. Como desvendar esta relação e chegar ao sentido que encerra? Só há um caminho. O sentido de qualquer enunciado pressupõe a consideração de um contexto não somente linguístico mas também prático e social (Jourdan e Tuite 2006): "O problema é o de descobrir a relação da linguagem com a 'vida real', isto é, com a praxis" (Lefebvre 1968 [1966]: 85), por outras palavras: "a passagem da língua para a vida e da vida para a língua"; ou ainda, "das estruturas linguísticas para as estruturas sociais e reciprocamente" 
(1968 [1966]: 85). Para tanto, há que situar no espaço e no tempo os processos de comunicação através dos quais se veiculam as representações (Jodelet 1989). Daí a valorização que o método regressivo-progressivo dá ao vivido e ao histórico. De facto, o vivido não pode ser desprovido da sua historicidade, o mesmo se podendo dizer em relação à linguagem. Dando um exemplo, não é por acaso que os historiadores têm dado uma especial atenção à relação entre movimentos migratórios e antroponímia (Salinero e Testón Núñez 2010). ${ }^{3}$ Nas roturas biográficas associadas aos processos de migração encontramos frequentes mudanças de nome entre os migrantes. Na Época Moderna, podia-se emigrar com o nome de um primo, adotar o nome da clientela de um protetor, eleger um pseudónimo que camuflasse uma trajetória de vida suspeita. Havia emigrantes que deixavam na terra de origem a sua identidade real, viajando com uma identidade fingida (Testón Núñez e Sánchez Rubio 2010). E porque nem sempre é fácil descobrir as identidades que sob os nomes se escondem, estes podem ser peças de um jogo de enganos.

Em suma, é no vivido que a linguagem ganha sentido: "A linguagem permite descrever e dizer situações [...]. O sentido provém de situações e regressa às situações" (Lefebvre 1968 [1966]: 295). Numa trama de mediações, o percebido desempenha o papel de intermediário (mediação) entre o vivido e o concebido (entre a vida e a reflexão). É a análise dialética (Martins 1996; Hess 1988) entre as dimensões do vivido, do concebido e do percebido que permite a esta última dimensão um lugar de evidência pela densidade e força que adquire nesse jogo de mediações. Através destas mediações descobrimos que no vivido a linguagem assume uma mais-valia, um valor distinto. É por isso que o sentido das palavras é mais difícil de atingir que o seu significado - já que este imobiliza o signo, não sendo por acaso que o signo fica inerte no significado. Ou seja, por detrás do limbo das palavras encontramos um amplo campo de análise social. Como decifrar os enigmas da linguagem? É esse desafio que nos move na busca do sentido de alguns palavrões.

\section{UM ESTUDO DE CASO: O ENIGMA DO CHÁ MISTERIOSO}

Há cerca de uma década realizei várias incursões etnográficas por Trás-os-Montes, na alçada do movimento das "Mães de Bragança". ${ }^{4}$ As "mães" pretendiam

3 A necessidade de cruzamento de estratégias de comparação etnográfica e histórica é também reivindicada por Pina-Cabral (2008) e ilustrada por Harris (2008) quando clarifica a influência portuguesa na prática de atribuição de nomes na história do Pará, confrontando os períodos colonial, imperial e contemporâneo.

4 Em Bragança, o trabalho de campo mais intensivo decorreu entre 2003 e 2008, período em que efetuei duas a três deslocações por ano, com estadias de uma a duas semanas. Posteriormente as visitas tornaram-se mais esporádicas. Para além de Bragança, deambulei por outras regiões de Trás-os-Montes, como Mirandela, Macedo de Cavaleiros e Vinhais. Quando as rusgas policiais às casas [continua] 
expulsar da cidade as trabalhadoras de sexo brasileiras, por elas apelidadas "putas" e "cabras". Durante a pesquisa (Pais 2011) fiquei surpreendido por as Mães acusarem "as brasileiras" de seduzirem os maridos com feitiços e macumbas. Falaram-me de um chá com o poder de "amarrar" os maridos. Nunca me revelaram o nome do misterioso chá. Questionado sobre o assunto, o proprietário de uma das mais conhecidas casas de alterne da cidade - então em prisão domiciliária - corroborou, sorridentemente, os poderes do chá. Logo que me revelou o nome, anotei-o, pois nunca ouvira falar da espécie revelada. Pensei tratar-se de um chá importado do Brasil, qualquer variedade exótica das muitas que El-Rei D. João VI de Portugal mandara cultivar, em 1811, no Jardim Botânico do Rio de Janeiro.

Quando, despreocupadamente, revelei o nome do chá a dois colegas brasileiros - um antropólogo e uma socióloga que me acompanharam no trabalho de campo $^{5}$ - arregalaram os olhos e, levando ambos a mão à boca, sustiveram uma gargalhada. A socióloga, assomada de pânico, advertiu-me: "Oi, Machado! Você não vai falar disso, não! Viu?! Por favor, Machado!” O antropólogo, buscando argumentos mais convincentes de dissuasão, advertiu-me que, numa universidade brasileira, um estudante que fizera uso do termo numa tese de mestrado tinha sido convidado a eliminá-lo, sob pena de poder vir a ser reprovado por ofensa à dignidade dos membros do júri. Liberta do termo incómodo, a tese saiu incólume do embaraço, aprovada com distinção e louvor. Apesar de, em Casa-Grande \& Senzala, Gilberto Freyre (1995 [1933]: 25 1) opinar que "a maior delícia do brasileiro é conversar safadeza”, tudo tem os seus limites. Acontece que a palavra que lavra mistério, de uso tão problemático no Brasil, é em Portugal uma palavra desusada e inócua, tendo o mesmo significado com que Machado de Assis a usou em Dom Casmurro (1899): o de uma simples caixa. Para não ferir suscetibilidades, ocorre-me ocultar o nome original do chá, imitando as personagens dos célebres livros de Harry Potter quando, por temor de referirem o nome tétrico de um tenebroso feiticeiro (Voldemort), a ele aludiam com uma insuspeita designação: o Quem Nós Sabemos. Seguindo a mesma estratégia, a entidade que dá nome ao milagroso chá poderá ser designada Quem Nós Sabemos. Inspirado em Lefebvre, apresento de seguida algumas hipóteses de investigação sobre o imbróglio que envolve o nome do chá. À frente delas uma ideia, um princípio orientador que desde já anuncio. Se não fizermos uma distinção entre as palavras "nuas e cruas" e os sentidos (literais ou obscuros) com que se vestem quando se cozinham umas com as outras, não fará sentido realizar análise de discurso e muito menos tomá-lo como um facto social. Bastaria enunciar

de alterne se intensificaram (Pais 2011), tendo muitas das trabalhadoras de alterne rumado para Espanha, realizei algumas incursões por Alcanices, Verin e Zamora. Dados mais aprofundados desta minha pesquisa etnográfica serão publicados num futuro livro.

5 Refiro-me a Ismael Pordeus Jr. (da Universidade Federal do Ceará) e Roselane Bezerra (bolseira de pós-doutoramento no Centro de Estudos Sociais da Universidade de Coimbra). 
as palavras, uma a uma, amarradas aos seus significados isolados e diretos. O chá de Quem Nós Sabemos é uma mistela que dá que pensar, não tanto por seus pretensos efeitos mágicos mas, sobretudo, por seus impactos semióticos e socioantropológicos.

\section{PALAVRÕES: O QUE MOSTRAM SOB O QUE ESCONDEM}

Uma vez que a nomeação de Quem Nós Sabemos é problemática quando dita no palavrão que dá nome ao misterioso chá, sobrevêm muitas outras nomeações que tenho vindo a reunir numa extensa base de dados que já ultrapassou o meio milhar de registos. Muitos destes nomes correspondem a designações que apenas identificam na base do subentendido, como se correspondessem a códigos cifrados que impedem de nomear diretamente o que, possivelmente, já terão suspeitado o que seja, mesmo quando ao abrigo de expressões redundantes como: a Inominável, Aquela, A Própria, A Que É, A Estranha, A Dita Cuja, Fulana, Ela, Elazinha, Toda-Toda. Apelidos que, desde logo, nos desvelam o género feminino da coisa nomeada. No fundo, são nomeações que envolvem um secretismo disfarçado, um falso anonimato, um incentivo ao burburinho, sinal de que Quem Nós Sabemos pode envolver-se em atividades clandestinas ou ilegítimas, daí que também ganhe o apelido de Não-Conta-Pra-Ninguém. O curioso é que o indizível termo recobre uma realidade à qual se diz que devemos a nossa existência. Um poeta popular brasileiro (Briguet), questiona-se: "O que seria de mim sem ela? Nem sequer eu nasceria [...], somos todos filhos dela”. E no entanto, arrastando uma dupla personalidade, Quem Nós Sabemos acaba por ser nomeada de Perseguidora e Perseguida, neste último caso podendo estar sujeita a humilhações e cominações. Num livro sobre A Medicina na Voz do Povo, um médico português (Costa 2007) revelou que uma sua doente, ao mesmo tempo que se lamentava da maleita que a trazia à consulta, logo pressagiou a causa: "Tenho esta comichão na Perseguida porque o meu marido tem uma infeção na ponta da natureza." ${ }^{\prime 6}$ Não se pense que os nomes integram um sistema arbitrário. Produzem-se no mundo de que fazem parte, no vivido. Eles escondem e revelam enigmas que deslizam dos atos de nomeação para as coisas nomeadas, e vice-versa.

Ao guerrearem-se entre si, os nomes acabam por gerar verdades que se relativizam ao contradizerem-se. Como sugere Barthes (1977: 39), "a linguagem é um topos guerreiro" - lugar de significados que se desprendem de signos, num deslizamento de sentidos e metáforas, dicções e contradições, significados que se pelejam por incapacidade de alcançarem o significante. Enquanto identificadores de afeto e intimidade, os diminutivos dados a

6 No seu livro, o médico dá conta de outras designações que se referem à Perseguida, como: Montadeira, Parreca ou Pardalona. 
Quem Nós Sabemos são abundantes, mas também surgem modalidades de tratamento formais, respeitosas ou distanciadas, do tipo Dona Pepa, Dona Felisbina ou Dona Vera. O nome personifica a existência, dá-lhe um cunho de individualidade. Porém, o que mais interessa na relação do nome com a coisa nomeada é o que está para além dessa relação. Os nomes funcionam como cartões de visita que, sobretudo, indicam quem é quem aos olhos de quem nomeia. Por isso mesmo, o espaço mítico constituído pela rapsódia de nomeações dadas a Quem Nós Sabemos é um espaço de códigos cujas significações conflituam entre si, não apenas em função do que podem representar mas, sobretudo, por corresponderem a construções intencionais, expressão de divisões sociais (Halliday 1978). Alguns repentistas brasileiros dão conta dessa realidade, sinalizando a possibilidade de o palavrão associado a Quem Nós Sabemos equivaler a uma contralinguagem demarcada do universo linguístico de classes abastadas: "O rico toca piano/ O pobre toca corneta/ O rico é que se masturba/ O pobre bate punheta/ Xana de rica é vagina/ Xana de pobre é [Quem Nós Sabemos]".

A criação imaginária ultrapassa os limites da representação na medida em que amplifica as simbolizações do que representa (Legros 1996). É o caso dos referenciais lúdicos associados a Quem Nós Sabemos quando é apelidada de Barbie, Bibelot, Boneca ou Ioiô. Podemos procurar paradigmas onomásticos que nos levem do nome à essência da coisa nomeada, mas esbarramos sempre em nomeações que descarrilam, ora como semantemas (noções ou categorias relativas à realidade), ora como morfemas (categorias de pensamento). A ordem do discurso converge frequentemente para representações estereotipadas e, quando assim acontece, muitas nomeações de Quem Nós Sabemos surgem como veículos de afirmação de um indisfarçável machismo. Estamos perante metaforizações que nos permitem compreender a realidade de uma coisa em função de imagens associadas a outra, incluindo a compreensão de identidades sociais a partir dos imaginários em que essas mesmas identidades se projetam. O que se sugere é que, frequentemente, os nomes dados a Quem Nós Sabemos simbolizam, metaforicamente, uma dominação masculina (Bourdieu 1998). Ou seja, os registos semânticos inventariados dão conta de uma dominação de género que estrutura o que se diz e o modo como se diz, um dizer que se afirma para além do que é dito (Guiraud 1978). No entanto, representações elogiosas coexistem com as temerosas, indiciando uma masculinidade ameaçada, ainda que ironicamente. Num tal registo, e numa época em que as redes terroristas proliferam, Quem Nós Sabemos aparece associada a enredos conspiratórios. Há quem não hesite em a apelidar de Talibã ou Bin Laden ou a descreva como um agente malfeitor: Perdição, Perigosa, Calamidade, Escraviza Homens, Desgraça de Macho. Outros apelidos sinalizam tendências macabras: Assassina de Palhaço, Bicho Que Mata o Homem, Cova do Defunto, Ali Onde Eu Me Acabo. Enfim, estamos perante nomeações que emergem, seguramente, 
de uma "comunidade discursiva" (Maingueneau 1984) - masculina, no caso -, evidência que não pode ser desprezada.

\section{PODERES OCULTOS}

A indizível é também apelidada arma de agressão, podendo o motejo ir de uma simples Machadada a um poderoso Canhão, passando por uma trivial Pistoleira. Ela é também vista como uma lutadora - Princesa Guerreira -, reunindo ainda predicados de domadora: Amansa Macho, Devoradora, ou Superpoderosa. Este último atributo parece ser reivindicado por algumas mulheres. Num livro, editado em Portugal, da brasileira Nelma Penteado, sugestivamente intitulado Os Segredos das Mulheres Brasileiras para Manter os Homens Loucamente Apaixonados, é dado às mulheres o conselho: "Use o termo poderosa [...]. Além do mais é um nome bonito que já deixa um homem ansioso para conhecer "tal poder" (2010: 116). O badalado poder de Quem Nós Sabemos foi também testemunhado por Pina-Cabral (2003: 55-86) quando, no Noroeste de Portugal, descobriu que negociantes e caçadores ficavam atemorizados sempre que se cruzavam com uma jovem viúva. Mau presságio para negócios e caçadas. Os negociantes queixavam-se de que os ganhos iam por água abaixo e os caçadores lamentavam-se de que as espingardas perdiam a pontaria, por isso friccionavam o cano das mesmas entre as pernas, contra os genitais, para corrigirem a pontaria. ${ }^{7}$ Como quer que seja, os poderes para gerar o mal também podem gerar o bem. Com efeito, se Quem Nós Sabemos tem sido considerada um Portal do Inferno, fonte de desgraças e sofrimentos, também aparece como um ícone: sagrada, venerada, possuidora da capacidade única de "dar à luz”. A incompatibilidade dogmática entre o bem e o mal desestrutura-se porque a realidade nomeada alberga forças contrárias, forçando-as à convivência. Em suma, no imaginário - principalmente no masculino, onde mais fervilham estas representações - há uma união de opostos: tese e antítese, ao mesmo tempo que síntese.

Ainda em relação aos poderes ocultos de Quem Nós Sabemos, na Catalunha havia o costume de as mulheres dos pescadores exporem os genitais ao mar antes de os maridos embarcarem. Acreditavam que, desse modo, o mar se acalmava - ao contrário do que sucederia se nele urinassem. A exposição dos genitais femininos é um recurso que tem sido usado, ao longo da História, para expulsar demónios, afugentar espíritos malignos, impedir que vários tipos de males aconteçam. Quando os perigos espreitam ou as adversidades ameaçam, a sabedoria popular de algumas culturas dita que a melhor opção de uma mulher é erguer as saias (Blackledge 2006 [2003]: 17-76). O mesmo recurso

$7 \quad$ No Rio Grande do Sul (Brasil) a má pontaria das espingardas poderia ser retratada com a expressão "embucetar" (Fisher 2004: 107). 
é usado em discussões e zaragatas públicas no Norte de Portugal. Numa delas observei que o levantamento das saias era acompanhado de fortes batimentos numa das nádegas pela mão oposta à que levantava a saia. Não é fácil explicar esta exposição deliberada ou insinuada dos genitais femininos, de que existem abundantes referências no folclore e na literatura. Tentativa de humilhar os adversários? De os seduzir? De os atarantar? Mera superstição? ${ }^{8}$ Uma coisa é certa, Quem Nós Sabemos arrasta um mito de poder e um poder mítico.

O mito do poder resvala para a incapacidade de o representar ou até mesmo de o nomear de uma forma unívoca. Daí a pluralidade contraditória das nomeações e representações de Quem Nós Sabemos. Esta ambivalência, de quem pode ser uma coisa e o avesso da mesma, ocorre também quando passamos em revista as suas representações religiosas. Ela é Deusa, Peregrina, Santinha, Irmã Maria, Imaculada, Dona Anja; ou então é vista como Paraíso, Vale Sagrado, Portal do Céu, Abençoada, Aba de Estrelas, Cricrita dos Céus, Estrela Guia, Luz no Fim do Mundo, Sino de Igreja, Milagrosa, Acolhedora dos Santos. Mas, lá está, os apodos vilipendiosos retratam-na também como Profana, Libertina, Fatal, Libidinosa, Sinistra, Pecado, Pecaminosa, Sem-Vergonha, Tentação do Diabo. O método regressivo-progressivo de Lefebvre ajuda-nos a compreender esta diabolização, onde as palavras se convertem num mito de arquipotência que, no caso em estudo, afirma o ser e o acontecer de uma idealizada essência feminina. Com efeito, nos tempos da Inquisição, a mulher era vista como um ser que facilmente se deixava cair em tentação, dada a suposta debilidade da sua fé na palavra de Deus (Cawthorne 2004). Como quer que seja, embora imaginariamente convertida em artesã demoníaca, Quem Nós Sabemos é capaz de destilar amor do mesmo modo que sortilégio. Ela é reversível porque polivalente. Divina e diabo. Mágica porque vista como tendo poderes sobrenaturais, por intervenção de Deus ou do Demónio. E uma vez que um dos atributos da magia é o de criar imagens (Mauss 2003 [1902-1938]), ela própria é ela mais as imagens a que dá lugar. Em suma, por ser uma realidade sulcada em todas as direções no imaginário do desejo ou do temor, ela pode assumir múltiplos nomes, saturando-se de analogias, metaforizações, alusões. $\mathrm{O}$ volumoso caudal de tão exóticas nomeações prova a incapacidade de acoitar sob um único nome realidades plurais em suas significações. A menos que esse nome se exceda de sentidos permitindo pensar-se o indizível, numa espécie de "síntese criativa" - expressão que Weber (1993 [1922]: 38-45) usava para dar conta de diversos tipos de conexões (psíquicas ou culturais). Esse nome existe, ainda que indizível. O pudor em o verbalizar esconde um enigma por desvendar.

8 A superstição (do latim superstitio) significava, originariamente, "o que persiste de épocas antigas". É neste sentido que - à luz do método regressivo-progressivo, proposto por Lefebvre (1968, 1983) - se pode tomar a superstição como uma sobrevivência, embora reelaborada, da tradição. 


\section{LINGUAGEM E PUDOR}

Como interpretar o pudor social que se projeta no uso dos palavrões? Qual a razão pela qual o nome que é dado ao chá misterioso é uma palavra maldita? Como bem o sugere Leach (1973 [1964]), a compreensão dos tabus linguísticos passa pela valorização do não dito, do interdito, do que socialmente produz a obscenidade. Quem Nós Sabemos poderia denominar-se "Órgão Sexual da Mulher" ou mesmo "Vagina", mas estas designações assépticas escondem o tabu que o palavrão denuncia às escancaradas, daí que o tétrico termo se tenha transformado num interdito linguístico, sucumbindo a rumores reverenciais, a uma decência social. Porém, o tabu continua presente em sua ausência. No lugar do palavrão surgem imensas designações substitutivas ou sucedâneas, que o tornam presente em sua ausência. Por outras palavras, os controles repressivos sobre a sexualidade libertam a imaginação na criatividade da linguagem. Não podemos menosprezar os mecanismos sociais que geram o processo de transformação simbólica de uma simples palavra num palavrão ou num prenúncio do mesmo. No caso em estudo, o tesouro da linguagem é um reservatório de imaginários que se alimentam de um cozinhado aparentemente incongruente, onde a ficção se entrelaça com o vivido na antecipação de um retorno imaginado a lugares de memória ou na projeção de desejos fantasiados ou reprimidos.

Dito isto, os corpos - representados no sexo e na sexualidade - ganham sentido cultural, na medida em que as palavras os habitam. Nos atos de nomeação, as palavras tatuam culturalmente os corpos. Essas tatuagens - entendidas como mediações - são formas de ler o social. Assim sendo, há que levar a sério os palavrões, deixando de lado a "autoridade etnográfica" arrogante (Clifford 1991) que desvaloriza as categorias nativas como chaves de interpretação do vivido. As metaforizações e tropismos (Fernandez 1991) que giram em torno de Quem Nós Sabemos permitem dar visibilidade ao indizível, em jogos de nomeação cujo encanto recrudesce com o vínculo de parentesco da ilusão com o mito (Lefebvre 1962; Lévi-Strauss 1978; Durand 1981). Jorge Luís Borges (1983: 178) caracterizou a literatura alegórica como uma fábula de abstrações, embora personificadas. O mesmo se passa com as nomeações alegóricas dirigidas a Quem Nós Sabemos. Elas acentuam aparentes singularidades que todavia se movem para um ideal - porque em mira não estão propriamente singularidades mas sim uma espécie; não as espécies mas sim um género; não os géneros mas sim uma divindade; não o múltiplo mas o uno: o "universal triunfante" sobre o "particular irredutível" (Appadurai 1996: 64). De qualquer forma, dá-se também uma simbiose entre duas realidades intrínsecas: uma material (substantiva) e outra formal (idealista). Num caso, Quem Nós Sabemos é um agente produtor de desejos, sensações e experiências a partir de sua existência singular e material. Noutro caso, ela é aquilo que faz de si o 
que é, a forma em que se encaixam todas as singularidades, pois o universal apenas é alcançável por mediação das partes. Ou seja: se existir é diferir, a diferença é, de certo modo, o lado substancial das coisas: o que elas têm de mais próprio e comum, apesar das qualidades que as singularizam, umas em relação às outras, como Tarde (1999 [1895]) bem o demonstrou em sua monadologia. Nesta dialética, o vivido (registo do experienciado) e o imaginado (registo do idealizado) convergem para o discurso (registo do significado). Os nomes vinculam-se a vidas vividas de coisas reais (Rosenstock-Huessy 2002 [1981]). Por isso mesmo, Quem Nós Sabemos é um lugar de circulação de sentidos, de condensação de imaginários e fantasias, um centro que é também lugar de topofilias e topofobias, uma territorialidade de medos e anseios, desejos e equívocos, excitações e proibições. Todos estes imaginários são mais do que meras imagens refletidas de uma qualquer realidade. São também criações incessantes de imagens que criam a sua própria realidade (Castoriadis 1975). Nela se enfileiram significações que remetem para distintas ordens de representações, ao convocarem o percebido, o vivido e o concebido. Uma outra questão é a de se saber por que razão há que buscar no imaginário um complemento necessário da ordem social. De uma ordem que suscita identidades imaginárias com roupagens simbólicas.

\section{DESLIZES E TRESMALHAÇÕES}

O método regressivo-progressivo permite-nos compreender por que razão a ilegitimidade de se dizer o que, por decoro moral, é indizível ganha novos sentidos a partir da articulação do vivido com o percebido e o concebido. Vejamos, mais em detalhe, um outro controverso nome que é dado a Quem Nós Sabemos - o de Cabra. O seu significado linguístico remete para um mamífero ruminante, fêmea do bode. No entanto, o sentido que a palavra desponta escapa-nos se não levamos em conta o seu contexto de uso, na alçada de uma historicidade que nos permita uma aproximação aos refluxos de significação do nome. Até há cerca de três ou quatro décadas, ainda existia no Norte de Portugal um rito denominado "pagamento da cabrita". Qual o sentido que aqui tem o termo cabrita? Usando o método regressivo-progressivo e resgatando a génese histórica da significação do termo, descobre-se que o antigo rito se projeta num universo de significações onde impera a ideia de uma ordem ocultamente prescrita. Os rapazes consideravam as moças de suas aldeias como propriedade interdita aos forasteiros. Nalguns casos, exerciam uma espécie de direito sobre as moças da terra que consistia em as apalpar quando circulavam pelas ruas (Fontes 1974: 106). E que acontecia se algum rapaz forasteiro pretendesse namorar como uma moça da aldeia? O direito somente era concedido mediante uma penalização, o pagamento da cabrita. Ao descobrirem que uma moça se deixava ir pelo "arrastar de asa" de um forasteiro, os rapazes da aldeia 
invadiam a casa dos pais da moça, quando o noivo lá estava, para o obrigar a sair e pagar as inevitáveis rodadas de vinho à rapaziada. Em caso de resistência ou insubmissão, era amarrado a uma corda e mergulhado numa fonte, num poço ou num rio. Convencido o noivo, rumavam todos para a primeira taberna que encontrassem, o noivo à frente e os rapazes da aldeia atrás, a cantar. Lá chegados, o noivo pagava vinho, pão e bacalhau para todos. Depois peregrinavam por outras tabernas da aldeia, comendo e bebericando (Lages 1983).

O pagamento da cabrita é, certamente, um rito integrativo. Porém, arrasta também a simbolização de um status quo. Por isso, o rito faz sentido porque ordena a desordem, conferindo meios para a controlar. Mas o rito não assegura uma integração plena. Mesmo tendo pago a cabrita, o noivo de terra alheia continua a ser olhado como "de fora". Se um rapaz que tivesse pago a cabrita por namorar uma moça de aldeia vizinha viesse a namorar com outra da mesma aldeia, de novo era sujeito ao pagamento da cabrita. A questão problemática é a de saber por que razão é que o noivo que vem de fora namorar ou casar com uma moça de uma dada aldeia se vê obrigado a uma punição. Para o efeito importa questionar o sentido oculto do termo cabra ou cabrita, no ritual que leva o seu nome. A hipótese de que uma pequena cabra (no sentido linguístico do termo) poderia ser "partilhada pelos convivas de um banquete" (Lages 1983: 660) levanta dúvidas. Recentemente, mobilizado por uma etnografia da comunicação (Saville-Troike 1989), visitei algumas aldeias do distrito de Viseu, onde também existia o rito do pagamento da cabrita. Questionei então alguns aldeãos sobre o significado do termo "cabrita": Era uma cabra que o noivo tinha de pagar? Em risadas negaram-me convictamente a hipótese, tendo-me alguns sugerido que a cabra era uma "ovelha tresmalhada", ou seja, a moça que tinha rejeitado os rapazes da aldeia para se juntar com um de fora. Também no Brasil colonial eram popularmente designados "cabras" todos os indivíduos que resultassem de indesejáveis misturas sociais. $\mathrm{O}$ atributo de cabra, por esse motivo, era depreciativo (Furtado 2003: 49). A cabra, tal qual a moça que se deixa levar por um rapaz de fora, caracteriza-se por uma rebeldia à domesticidade. Embora presas nos fundos das casas (as cabras) ou, em sentido alegórico, nas próprias casas (as moças que têm noivo de fora), o que parece caracterizar umas e outras é o risco de evasão que exige uma contrapartida, uma pena, uma multa ou mesmo uma retaliação: o pagamento da cabrita. Mais uma vez, o que o nome Cabra encobre é uma relação de poder em que a denominação masculina confina a mulher à esfera doméstica, realidade que aparece refletida em muitos adágios populares (por exemplo: "do homem a praça, da mulher a casa").

Aqui chegados, que representa, afinal, a cabrita? Desde logo, o termo parece apontar para uma necessidade social de simbolização das relações sociais. Neste sentido, a cabrita parece assumir uma dupla valência: quer como valor de transação (equivalente geral de trocas), quer como objeto transacionável 
(associado a um valor de uso). Ora bem, se a cabra, em termos simbólicos, representa a moça que saltou a cerca da sua comunidade de origem, então justifica-se a relação contratual entre os rapazes da aldeia (que perdem a cabrita) e o noivo (que a ganha) através de um pagamento que representa nem mais nem menos que o preço da cabra. Esta hipótese - vou chamar-lhe hipótese de tresmalhação - faz algum sentido, até na medida em que sabemos que os pastores que guardam rebanhos consideram as cabras muito mais ariscas do que, por exemplo, as ovelhas. Por isso mesmo, a designação de cabra também é dada a uma mulher de comportamento duvidoso, suspeito, indigno. Aliás, "puta" e "cabra" são palavras frequentemente usadas como sinónimos (Millet 2001). Neste registo analítico, o apelido de Cabra que é dado a Quem Nós Sabemos pode ser sintoma de uma suspeitada ameaça de "dor de corno" - para usar outro palavrão popular, também cheio de sentido.

O simbolismo dos cornos tem sido bastante estudado na antropologia. A sua interpretação não pode dissociar-se dos contextos sociais de uso que lhe dão sentido e que remetem para a um código de honra baseado na força e na virilidade. Um homem cornudo é um cabrão, sendo os cornos atributo de um marido ou amante enganado - devido à sua passividade, como acontece com o bode, por ser condescendente com o acesso de outros machos às fêmeas do seu domínio (Leach 1973 [1964]; Blok 1981). Por a sexualidade das mulheres ameaçar a honra dos homens, estes defendem-se procurando protegê-las do assédio por parte de outros homens. A defesa da honra e reputação justifica as ameaças de violência aos que se esquivam ao pagamento da cabrita: o mergulho numa fonte ou num poço. No fundo, os forasteiros são obrigados a submeter-se à força do rito, ou melhor, ao domínio dos que reivindicam a "imunidade do seu domínio" (Blok 1981: 17). Se o não fizessem passariam por "panhonhas" ou, pior ainda, por "bois mansos", sem os "tomates" no lugar.

A hostilidade entre aldeias, por efeito de ameaça aos casamentos endogâmicos, ligados a interesses patrimoniais, justifica não só a existência do rito do pagamento da cabrita como muitos dos apelidos que os nativos de aldeias vizinhas jogam entre si. Frequentemente, há uma tendência para se desvalorizar o status das mulheres que não são da terra. Por isso, no Alentejo surgem ditos do tipo: "As do Campinho são bruxas; de São Marcos, feiticeiras; da Cumeada, manhosas; de Reguengos, borracheiras" (Morais 2006: 53). As mulheres da freguesia de Nossa Senhora de Machede (concelho de Évora) são alvo de troça pois delas se diz que "não têm calcanhares" porque "caem facilmente de costas”, isto é, manifestam-se disponíveis para prazeres de cama. Para defenderem a reputação dos homens da sua terra, as mulheres atingidas costumam replicar que os homens "de fora", por virilidade duvidosa, "não têm biqueiras" (Morais 2006: 77-78). Também se diz que os habitantes da referida aldeia recusaram a edificação de uma escola ("não precisamos dela que nós cá somos todos analfabetos") mas, apregoavam os das aldeias rivais, reivindicavam a construção 
de uma praça de touros, dada a abundância de "cornos". Há pois uma clara oposição entre "os de cá" e "os de fora", "nós" e "eles", oposição presente quer em adágios (Pais 1985), quer em muitos ritos e tradições populares de Portugal, como nos festejos de São João, onde há um enfrentamento entre grupos rivais, designados Bugios (representando cristãos) e Mourisqueiros (representando forasteiros), ambos os grupos compostos por rapazes solteiros (Ferreira e Perdigão 2003: 14). Esta oposição manifesta-se em alguns ditos populares que envolvem aldeias vizinhas, desencorajando os casamentos exolocais. Por exemplo: "Eu casei-me na Mutela com uma moça de feição; de bonita não tinha nada, pobre sim, honrada não" (Dias 1984: 293). A tresmalhação é alvo de crítica social na convicção de que "quem fora vai casar ou foi enganado ou vai enganar", embora sejam interesses patrimoniais - não confessos mas reais que determinem esta representação, também presente nas loas das festas dos rapazes em Trás-os-Montes (Godinho 2006a, 2006b).

O ritual é um domínio privilegiado para desvendar cristalizações sociais de uma cultura, assim como suas transformações. Atualmente, já não são denominadas cabras as moças que saem de uma aldeia para namorar ou casar com rapazes de terra alheia. Em contrapartida, as Mães de Bragança que recentemente se revoltaram contra as trabalhadoras de sexo brasileiras, para além de as acusarem de enfeitiçar os maridos com o misterioso chá, também as apelidam cabras. Ou seja, as chamadas cabras vêm agora de fora, sendo alvo de múltiplas discriminações: enquanto mulheres, estrangeiras, imigrantes e prostitutas. A sua representação, de ameaçadoras intrusas, resulta da constatação de uma outridade como perigosa, caótica, indutora de desordem e insegurança. Por isso são apodadas de cabras, tendo desencadeado, no auge do movimento das Mães de Bragança, fervores patrióticos, nacionalistas, chauvinistas, xenófobos (Pais 2011). As apelidadas cabras aparecem como bode expiatório de uma desordem social. A casa de família é o lugar da mulher recatada e casta; os bordéis são, em contrapartida, o território da maldade erotizada. No universo feminino, o confronto entre "estabelecidos" e "outsiders" (Elias e Scotson (1994 [1965]) pode ser lido como decorrente de uma oposição entre ordem e desordem. Umas reivindicam o papel de mães, outras são simplesmente olhadas como cabras. Em contrapartida, quando o apodo de Cabra se refere a Quem Nós Sabemos, partindo das hostes masculinas, o que está em causa, a nível do inconsciente, é um possível temor de desordem, por efeito de poderes ameaçados por uma crescente emancipação feminina (Romaine 1999): suspeitas, ciumeiras ou desconfianças de possíveis ou imaginadas traições que acabam por se transformar em obsessão entre homens que teimam em defender que "em casa manda ela, mas nela mando eu". A alienação encontra-se também nas representações do vivido enquanto formas de consciência mitificada. A cabra aparece como um símbolo, mas são as analogias que dão razão de ser ao símbolo: "A comparação, a analogia, a identidade parcial (fictícia ou real) 
entram na consciência do símbolo. O simbolismo assim considerado supõe sempre dois termos, condensados num só por um tropo (elipse, metáfora)" (Lefebvre 1968 [1966]: 225). O sentido cai frequentemente no simbolismo. Porém, o símbolo reveste-se de sentido na medida em que subentende um imaginário social (distinto da imaginação individual) historicamente resgatável.

Para enfatizar a importância dos códigos de variabilidade dos nomes, seja tomado o exemplo de um outro palavrão que remete para uma entidade que frequentemente se relaciona com Quem Nós Sabemos. Poderia reproduzir o palavrão, mas, em seu lugar, limito-me a usar um termo corrente no Brasil para designar qualquer entidade: o "cara". Façamos então uma reflexão sobre os códigos de variabilidade do significado do cara a partir de um contexto concreto de comunicação. O caso aconteceu, recentemente, no Norte de Portugal. ${ }^{9}$ Um cabo da Guarda Nacional Republicana, irritado por não ter conseguido uma troca na escala de serviço, virou-se para o sargento responsável do escalonamento e desabafou, num misto de frustração e resignação: "não dá p'ra trocar, então pró cara...!" Sentindo-se atingido na sua honra e consideração, o superior hierárquico acusou-o de crime de insubordinação. Nos tribunais, os juízes tiveram de se enfrentar não propriamente com o significado denotativo do Cara, que ninguém contesta, mas com o valor moral do cara, determinado pelo contexto de uso. Dependendo deste, talvez o palavrão não fosse assim tão injurioso ou ofensivo. Por aqui vemos que, dependendo do contexto de comunicação, há palavras que podem promover ou abalar hierarquias sociais. O guarda salvou-se da condenação porque, como Garfinkel (2006 [1968]) bem o demostrou em seus estudos etnometodológicos, nas suas decisões os juízes respeitam, geralmente, as características rotineiras da ordem social. De facto, no Norte de Portugal o Cara aparece como uma verdadeira muleta oratória, para além de ser uma expressão popular de impaciência ou espanto. Aliás, em suas origens, o cara tinha uma significação inócua. Derivando do latim caraculus designava uma simples estaca e, talvez por isso, no tempo das descobertas marítimas, o termo cara era usado pelos marinheiros portugueses para designar o mastro principal das caravelas. Por aqui vemos que as palavras têm uma "génese histórica" (Lefebvre 1953), pois em cada época há modos legítimos de argumentar, narrar, persuadir, provar (Angenot 2010). Como também vimos na tentativa de interpretação do ritual do pagamento da cabrita, a génese não exclui "a análise das relações mais ocultas, de filiações perdidas" (Lefebvre 1983 [1980]: 17), mas também não impede o ganho de novos sentidos. É aqui que emerge a componente "histórico-genética" do método regressivo-progressivo. Se, como bem disse Galeano (2004: 21), "o nome é a coisa que o nome

9 O caso ocorreu em agosto de 2009, tendo a denúncia seguido para o DIAP (Departamento de Investigação e Ação Penal) de Lisboa, seguindo depois para o Tribunal de Instrução Criminal, até chegar, finalmente, ao Tribunal da Relação de Lisboa, em outubro de 2010. 
chama", ideia que aparece no seu livro As Palavras Andantes, também é verdade que uma mesma palavra pode significar muitas coisas diferentes, dependendo de por onde ela circule. Pergunta Lefebvre (1968 [1966]: 71): "Donde, como, de que coisa vem o sentido?" Não vem apenas da significação das palavras isoladas. Vem, sobretudo, dos seus contextos de uso e de suas ressonâncias culturais, das representações que arrastam. Como bem nos ensinou Lefebvre (1968 [1966]: 94, 1983 [1980]: 199-200), as representações sociais não são simples efeitos: são factos de palavras e, sobretudo, de práticas e lugares (Pink 2012).

\section{NOTAS CONCLUSIVAS}

Na carta escrita a Octavio Paz - que não lhe chegou a endereçar - e que abre La présence et l'absence, Lefebvre colocava a descoberto os ardis da linguagem, isto é, a sua natureza enigmática, por efeito das "dependências e poderes ocultos sob as palavras e os gestos” (1983 [1980]: 10-11). Daí o largo passo em frente que Lefebvre dá em relação à filosofia da linguagem, que a toma como um mero saco de palavras, a cada palavra se associando uma coisa ou uma ideia. Os poderes ocultos que transformam uma palavra num palavrão foram aqui pesquisados a partir de um termo indizível na língua portuguesa falada no Brasil, fora dos circuitos da clandestinidade ou do calão. O facto de, em Portugal, essa palavra arcaica ter um significado que nada tem de obsceno, dado significar uma "pequena caixa", mostra bem como as palavras têm uma história de vida e ganham um poder (Fairclough 1989) dependente dos contextos de uso: "A significação parece clara e bem definida; mas muda com o valor [...]. O contexto torna-se determinante" (Lefebvre 1968 [1966]: 94-95). As próprias onomatopeias só significam o que exprimem quando reportadas a um contexto de uso (Newmeyer 1989; Chambers 2003). Só o contexto comunica o valor da palavra. É também o que se passa com as palavras polissémicas, onde a relação entre significante e significado aparece obscurecida. Mesmo as palavras que parecem ter um significado indiscutível são portadoras de histórias de vida que alojam outros sentidos, dependendo do contexto de uso, como verificámos com as metaforizações de "cabra" ou do polivalente "cara". Ou seja, os nomes são mais do que cortinas que ocultam o movimento da linguagem, mais do que palavras amortalhadas em significados (Foley 1997). São códigos de variabilidade social que refletem e produzem o social e, por isso mesmo, ajudam a percebê-lo. Como qualquer mercadoria, a linguagem possui um valor na medida em que não se pode nomear sem representar. Por isso mesmo, pela sua natureza comunicativa, a linguagem concretiza-se como uma mediação entre o individual e o social (Lutfi 2003).

No estudo de caso aprofundado vimos que o palavrão indizível - que neste texto ganhou a alcunha de Quem Nós Sabemos - denuncia uma ausência que se enche de presenças ficcionadas, ao representar-se através de múltiplas 
imagens e propriedades. Sem estas, estaríamos perante uma abstração oca, uma sombra, um vazio em busca de seu próprio ser. É certo que o corpo apenas se representa através de investimentos abstratos: os signos corporais. No entanto, no intervalo que desune o corpo das suas representações primárias emerge uma outra realidade: um poder de nomeação. Ele gera-se a partir do vivido, palco de ebulição e circulação das representações sociais. E porque assim é, Quem Nós Sabemos acaba por não extravasar as representações triviais que a representam, pela simples razão que, como nos ensinou Lefebvre, o individual apenas se representa no social, pelo social e para o social. Todos os nomes que Quem Nós Sabemos ganha apenas a representam indiretamente, tornando-a presente em sua ausência através de múltiplas alusões, metáforas e simbolizações.

Nas mediações entre as nomeações e representações, o método regressivo-progressivo fez-nos descobrir uma tensão entre coação e libertação, tabu e remissão, alienação o obsessão. O interdito - a nomeação do palavrão - gera o prazer do contradito, uma forma de contornar o interdito a partir de outros ditos, ficando assim superada, de certa forma, a coerção que impede a circulação do palavrão. Esse prazer de rebeldia é claramente sinalizado pela natureza jocosa dos apelidos. Podemos mesmo falar de um "prazer de disparatar", usando uma expressão que é grata a Freud (2000 [1905]) quando analisa a relação do chiste com o inconsciente. A psicogénese do chiste, desenvolvida por Freud, mostra bem como o prazer de disparatar se pode interpretar como uma fuga à coercividade (psíquica ou social) que procede de um jogo criativo de palavras que procura "proteger o prazer contra a sua supressão" (Freud 2000 [1905]: 131). De facto, os apelidos atribuídos a Quem Nós Sabemos dão claros sinais de corresponderem a uma liberdade de jogar com ideias, representações e analogias que produzem o chiste. O prazer de disparatar parece também corresponder a uma fonte de prestígio, caso contrário os apelidos não circulariam, ou seja, não sobreviveriam. É como se a capacidade de nomear fosse equivalente a um poder de exibição quando a comunicação sobre a sexualidade se faz de forma jocosa. É nestas circunstâncias que desponta a possibilidade de toda esta criatividade antroponímica se associar a desejos reprimidos ou intensificados por razões desconhecidas da consciência. Aliás, uma grande parte dos apelidos atribuídos a Quem Nós Sabemos correspondem a elaborações oníricas, como acontece nos sonhos (Freud 1999 [1899]).

Muitos dos nomes que afugentam o palavrão sugerem a hipótese de os desejos reprimidos suscitarem múltiplas representações que alimentam imaginários sociais (Harvey e Shalom 1997). Estes, por sua vez, parecem dar sustentabilidade a uma hipótese levantada por Lefebvre: a transformação do sexual em obsessão e ficção. E tudo isto porque o sexual (a coisa que o palavrão designa) se converteu numa figura de ausência, por efeito de sua presença obsessiva: "Mesmo a desnudez, em vez de descobrir uma presença (como na arte clássica) divulga-se como imagem, como ausência" (Lefebvre 
1983 [1980]: 182). Finalmente, quanto aos poderes ocultos que transformam uma palavra num palavrão, o estudo de caso sobre Quem Nós Sabemos sugere a existência de importantes processos de mediação simbólica entre diferentes sexos. Algumas pesquisas têm mostrado como a linguagem se associa a identidades de género (Bergvall, Bing e Freed 1996; Cameron 1995; Mills 1995), mas raramente se têm discutido as dimensões de alienação na forma como essas identidades se jogam nos palavrões. Para o efeito, há que valorizar o poder semiológico das nomeações. Como acontece com os mitos, os palavrões vestem-se de roupagens simbólicas que a linguagem projeta no pensamento e nos imaginários sociais.

\section{BIBLIOGRAFIA}

ANDERSON, Lars, e Peter TRUDGILL, 1990, Bad Language. Oxford, Basil Blackwell.

ANGenot, Marc, 2010, El Discurso Social: Los Limites Históricos de lo Pensable e lo Decible. Buenos Aires, Siglo XXI Editores.

APPADURAI, Arjun, 1996, Modernity at Large: Cultural Dimensions of Globalization. Minneapolis e Londres, University of Minneapolis Press.

ARANGO, Ariel, 1996, Dirty Words: The Expressive Power of Taboo. Northvale, NJ, Aronson. ARrIVÉ, Michel, 2007, A la recherche de Ferdinand de Saussure. Paris, Presses Universitaires de France.

BARTHES, Roland, 1977, O Prazer do Texto. São Paulo, Perspectiva.

BERGVALL, Victoria, Janet BING, e Alice FREED (orgs.), 1996, Rethinking Language and Gender Research: Theory and Practice. Londres e Nova Iorque, Longman.

BLACKLEDGE, Catherine, 2006 [2003], A História da V:: Abrindo a Caixa de Pandora. Lisboa, Lua de Papel.

BLOK, Anton, 1981, "Carneiros e cabrões: uma oposição-chave para o código mediterrânico de honra", Estudos Contemporâneos, 2-3: 9-30.

BORGES, Jorge Luís, 1983, Novas Inquirições. Lisboa, Editorial Querco.

BOURDIEU, Pierre, 1998, La domination masculine. Paris, Editions du Seuil.

BUTLER, Chris, 2012, Henri Lefebvre: Spatial Politics, Everyday Life, and the Right to the City. Nova Iorque e Londres, Routledge.

CAMERON, Deborah, 1995, Verbal Hygiene. Londres e Nova Iorque, Routledge.

CAMERON, Deborah, e Don KULICK, 2003, Language and Sexuality. Cambridge, Cambridge University Press.

CASTORIADIS, Cornelius, 1975, L'institution imaginaire de la société. Paris, Editions du Seuil. CAWTHORNE, Nigel, 2004, Witches: History of a Persecution. Londres, Arcturus.

CHAMBERS, J.K., 2003, Sociolinguistic Theory: Linguistic Variation and its Social Significance. Oxford, Blackwell. 
CLIFFORD, James, 1991, "Sobre la autoridad etnográfica”, em C. Reynoso (org.), El Surgimiento de la Antropología Postmoderna. México, Gedisa, 141-170.

COSTA, Carlos Barreira da, 2007, A Medicina na Voz do Povo. Queluz, Círculo Médico.

DIAS, Jorge, 1984, Rio de Onor: Comunitarismo Agro-Pastoril. Lisboa, Editorial Presença (3. ${ }^{\mathrm{a}}$ edição).

DURAND, G., 1981, Las Estructuras Antropológicas de lo Imaginário. Madrid, Taurus.

ELDEN, Stuart, 2004, Understanding Henri Lefebvre: Theory and the Possible. Londres e Nova Iorque, Continuum.

ELIAS, Norbert, e John L. SCOTSON, 1994 [1965], The Established and the Outsiders. Londres, Sage.

FAIRCLOUGH, Norman, 1989, Language and Power. Londres e Nova Iorque, Longman.

FERNANDEZ, James (org.), 1991, Beyond Metaphor: The Theory of Tropes in Anthropology. Stanford, Stanford University Press.

FerreirA, Hélder, e Teresa PERDigÃO, 2003, Máscaras em Portugal. Lisboa, Mediatexto.

FISHER, Luís Augusto, 2004, Dicionário de Porto-Alegrês. Porto Alegre, Artes e Ofícios.

FOLEY, William A., 1997, Anthropological Linguistics: An Introduction. Oxford, Blackwell.

FONTES, António Lourenço, 1974, Etnografia Transmontana I: Crenças e Tradições de Barroso. Vilar de Perdizes, edição do autor.

FOUCAULT, Michel, 1966, Les mots et les choses: une archéologie des sciences humaines. Paris, Gallimard.

FOUCAULT, Michel, 1969, L'archéologie du savoir. Paris, Gallimard.

FOUCAULT, Michel, 1971 , L'ordre du discours. Paris, Gallimard.

FREUD, Sigmund, 1999 [1899], The Interpretation of Dreams. Oxford, Oxford University Press.

FREUD, Sigmund, 2000 [1905], El Chiste y Su Relación con lo Inconsciente. Madrid, Alianza Editorial.

FREYRE, Gilberto, 1995 [1933], Casa-Grande \& Senzala. Rio de Janeiro, Record.

FURTADO, Júnia Ferreira, 2003, Chica da Silva e o Contratador dos Diamantes. São Paulo, Companhia das Letras.

GAlEANO, Eduardo, 2004, As Palavras Andantes. Porto Alegre, L\&PM.

GARFINKEL, Harold, 2006 [1968], Estudios en Etnometodología. Barcelona, Anthropos Editorial.

GODINHO, Paula, 2006a, "As 'loas' que contam uma festa: permanência e mudanças na festa dos rapazes", em B. Pereira (org.), Rituais de Inverno com Máscaras. S/1., Instituto Português de Museus.

GODINHO, Paula, 2006b, O Leito e as Margens: Estratégias Familiares de Renovação e Situações Liminares no Alto Trás-os-Montes Raiano (1880-1988). Lisboa, Colibri.

GUIRAUD, Pierre, 1978, Sémiologie de la sexualité. Paris, Payot.

HALLIDAY, Alexander Kirkwood, 1978, Language as a Social Semiotic: The Social Interpretation of Language and Meaning. Londres, Arnold.

HARRIS, Mark, 2008, "Uma história de nomes: a alcunha, o primeiro nome e o apelido no Pará, norte do Brasil”, Etnográfica, 12 (1): 215-235.

HARVEY, Keith, e Celia SHALOM (orgs.), 1997, Language and Desire: Encoding Sex, Romance and Intimacy. Londres e Nova Iorque, Routledge.

HESS, Rémi, 1988, Henri Lefebvre et l'aventure du siècle. Paris, Métaillié.

JAY, Timothy, 2009, "The utility and ubiquity of taboo words", Perspectives on Psychological Science, 4 (2): 153-161. 
JODELET, Denise, 1989, Les représentations sociales. Paris, Presses Universitaires de France.

JOURDAN, Christine, e Kevin TUITE (orgs.), 2006, Language, Culture and Society. Cambridge, Cambridge University Press.

KARSENTI, Bruno, 1997, L'homme total: sociologie, anthropologie et philosophie chez Marcel Mauss. Paris, Presses Universitaires de France.

LAGES, Mário, 1983, "O casamento exolocal numa aldeia da Beira Alta", Análise Social, XIX (77-79): 645-665.

LEACH, Edmund, 1973 [1964], "Anthropological aspects of language: animal categories and verbal abuse", em Eric H. Lenneberg (org.), New Directions in the Study of Language. Cambridge, MA, The MIT Press, 23-63.

LEFEBVRE, Henri, 1953, "Perspectives de sociologie rurale", Cahiers Internationaux de Sociologie, XIV: 122-140.

LEFEBVRE, Henri, 1962, "Les mythes de la vie quotidienne", Cahiers Internationaux de Sociologie, XXXIII: $67-74$.

LEFEBVRE, Henri, 1968 [1966], A Linguagem e a Sociedade. Lisboa, Ulisseia.

LEFEBVRE, Henri, 1983 [1980], La Presencia y la Ausencia: Contribución a la Teoría de las Representaciones. México, Fondo de Cultura Económica.

LEFEBVRE, Henri, 1989 [1959], La somme et le reste. Paris, Méridiens Klincksieck.

LEGROS, Patrick, 1996, Introduction à une sociologie de la création imaginaire. Paris, L'Harmattan. LÉVI-STRAUSS, Claude, 1978, Mito y Significado. Madrid, Alianza Editorial.

LUTFI, Eulina Pacheco, 2003, "Lefebvre et les fondements théoriques des représentations", La Somme et le Reste, 2: 13-17.

MAINGUENEAU, Dominique, 1984, Genèses du discours. Liège, Mardaga.

MARTINS, José de Souza (org.), 1996, Henri Lefebvre e o Retorno à Dialética. São Paulo, Hucitec.

MARTINS, José de Souza, 2003, "Les temporalités de l'histoire dans la dialectique de Lefebvre”, La Somme et le Reste, 2: 6-12.

MATtiello, Elisa, 2008, An Introduction to English Slang: A Description of its Morphology, Semantics and Sociology. Milano, Polimetrica.

MAUSS, Marcel, 2003 [1902-1938], "Esboço de uma teoria geral da magia”, em M. Mauss, Sociologia e Antropologia. São Paulo, Cosac \& Naify, 48-181.

MELANDRI, Enzo, 1968, La Linea e il Circolo: Studio Logico-Filosofico sull'Analogia. Bolonha, Il Mulino.

MILleT, Catherine, 2001, A Vida Sexual de Catherine M. Porto, Asa.

MILLS, Sara, 1995, Language and Gender: Interdisciplinary Perspectives. Londres e Nova Iorque, Longman.

MORAIS, J.A. David de, 2006, Ditos e Apodos Colectivos: Estudo de Antropologia Social no Distrito de Évora. Lisboa, Edições Colibri.

NEWMEYER, Frederich J., 1989, Language: The Socio-Cultural Context. Cambridge, Cambridge University Press.

NICHOLS, Johanna, 1992, Linguistic Diversity in Space and Time. Chicago, The University of Chicago Press.

PAIS, José Machado, 1985, “De Espanha nem bom vento, nem bom casamento: sobre o enigma sociológico de um provérbio português”, Análise Social, XXI (86): 229-243.

PAIS, José Machado, 2002, Sociologia da Vida Quotidiana: Teorias, Métodos e Estudos de Caso. Lisboa, Imprensa de Ciências Sociais [edição brasileira: Vida Cotidiana: Enigmas e Revelações. São Paulo, Cortez Editora, 2003]. 
PAIS, José Machado, 2011 , "Mothers, whores and spells: tradition and change in Portuguese sexuality”, Ethnography, 12 (4): 445-465.

PENTEADO, Nelma, 2010, Os Segredos das Mulheres Brasileiras para Manter os Homens Loucamente Apaixonados. Alfragide, Publicações Dom Quixote.

PINA-CABRAL, João de, 2003, O Homem na Família: Cinco Ensaios de Antropologia. Lisboa, Imprensa de Ciências Sociais.

PINA-CABRAL, João de, 2008, "Recorrências antroponímicas lusófonas", Etnográfica, 12 (1): 237-262.

PINK, Sarah, 2012, Situating Everyday Life. Londres, Sage.

RABINOW, Paul, 1986, "Representations are social facts: modernity and post-modernity in Anthropology", em J. Clifford e George E. Marcus (orgs.), Writing Culture: The Poetics and Politics of Ethnography. Berkeley, Los Angeles e Londres, University of California Press.

ROBINSON, W. Peter, 2003, Language in Social Worlds. Oxford, Blackwell.

ROMAINE, Suzanne, 1999, Communicating Gender. Mahwah, NJ, Erlbaum.

ROSENSTOCK-HUESSY, Eugen, 2002 [1981], A Origem da Linguagem. Rio de Janeiro, Editora Record.

SALINERO, Gregório, e Isabel TESTÓN NÚÑEZ (orgs.), 2010, Un Juego de Engaños: Movilidad, Nombres y Apellidos en los Siglos XV a XVII. Madrid, Casa de Velázquez.

SANDMANN, Antônio José, 1993, “O palavrão: formas de abrandamento", Revista Letras, 42: $221-226$.

SARTRE, Jean-Paul, 2002 [1960]), Crítica da Razão Dialética. Rio de Janeiro, DP\&A Editora. SAUSSURE, Ferdinand de, 1997 [1916], Cours de linguistique générale. Paris, Payot.

SAVILlE-TROIKE, Muriel, 1989, The Ethnography of Communication. Oxford, Blackwell.

SHIELDS, Rob, 1999, Love and Struggle: Spatial Dialectics. Londres, Routledge.

STANEK, Lukasz, 201 1, Henri Lefebvre on Space: Architecture, Urban Research, and the Production of Theory. Minneapolis, University of Minnesota Press.

TARDE, Gabriel, 1999 [1895]), Monadologie et sociologie. Paris, Les Empêcheurs de Penser en Rond.

TESTÓN NÚÑEZ, Isabel, e Rocío SÁNCHEZ RUBIO, 2010, “Identidad fingida y migraciones atlánticas (siglos XVI-XVIII)”, em Gregório Salinero e Isabel Testón Núñez (orgs.), Un Juego de Engaños: Movilidad, Nombres y Apellidos en los Siglos XV a XVII. Madrid, Casa de Velázquez, 87-101.

Weber, Max, 1993 [1922], Metodologia das Ciências Sociais (Parte 1). São Paulo, Cortez Editora. 